\section{Kidney \\ Blood Pressure \\ Research}

\title{
Parathyroidectomy Reduces Intradialytic Hypotension in Hemodialysis Patients with Secondary Hyperparathyroidism
}

\author{
Chia-Jen Shih ${ }^{a, b, c} \quad$ Der-Cherng Tarng ${ }^{a, b} \quad$ Wu-Chang Yang ${ }^{a, b} \quad$ Chih-Yu Yang ${ }^{a, b}$
}

aDivision of Nephrology, Department of Medicine, Taipei Veterans General Hospital; 'bSchool of Medicine, National Yang-Ming University, Taipei; 'Department of Medicine, Taipei Veterans General Hospital, Yuanshan Branch, Yilan, Taiwan

\section{Key Words}

Secondary hyperparathyroidism - Intradialytic hypotension • Parathyroidectomy • End-stage renal disease

\begin{abstract}
Background: Secondary hyperparathyroidism is associated with vascular calcification and arterial stiffness in patients with end-stage renal disease. The aim of this study was to analyze the frequency of intradialytic hypotension (IDH) and cardiovascular function before and after parathyroidectomy (PTX) in maintenance hemodialysis patients. Methods: We compared predialytic and intradialytic blood pressure, left and right ventricular ejection fraction (LVEF and RVEF), and cardiothoracic ratio 1 month before PTX, and 6 and 12 months after PTX. IDH was defined as a decrease in systolic blood pressure $\geqq 20 \mathrm{mmHg}$ or a decrease in mean arterial pressure $\geqq 10 \mathrm{mmHg}$. Results: At the time of PTX, the mean age of the patients was $57.4 \pm 12.0$ years, and the mean dialysis vintage was $12.2 \pm 5.8$ years. At baseline, 6 months, and 12 months after PTX, the average numbers of sessions disturbed by IDH during 13 dialysis sessions ( 1 month) were $6.4,3.9$ ( $p<0.016$ vs. baseline), and 4.0 sessions ( $p<0.037$ vs. baseline, $p=0.801$ vs. 6 months), respectively. LVEF and RVEF were improved significantly after PTX. Furthermore, volume status was also improved, as evidenced by the significantly greater ultrafiltration volume and reduced cardiothoracic ratio. Conclusions: Hemodialysis patients with severe secondary hyperparathyroidism are more likely to achieve normotensive and euvolemic status after PTX, probably through improved heart function and reduced IDH episodes.
\end{abstract}

Copyright $@ 2013$ S. Karger AG, Basel

\section{Introduction}

Secondary hyper-parathyroidism (SHPT) is a common complication of patients with endstage renal disease (ESRD). Elevated parathyroid hormone (PTH) levels may be associated 


\section{Kidney \\ Blood Pressure Research}

with increased risks of mineral bone disorders, vascular calcification, and cardiovascular mortality [1]. Parathyroidectomy (PTX) is reserved for medically refractory SHPT. Drastic reductions in PTH and phosphate levels after PTX may lead to improved blood pressure (BP) and arterial stiffness [2, 3].

In patients with ESRD, increased arterial stiffness, known as reduced vascular compliance, may contribute to higher systolic BP, widened pulse pressure (PP), increased left ventricular hypertrophy, and even cardiovascular mortality [4, 5]. Arterial stiffness may have a negative impact on hemodynamic stability due to inadequate effective volume autoregulation, especially during ultra-filtration [6]. In addition, there is increasing evidence of an important link between arterial stiffness and intra-dialysis hypotension (IDH) [7, 8]. Whether or not arterial stiffness and IDH improve after PTX remains unknown. Frequent episodes of IDH may cause reduced ultra-filtration, inadequate "dry weight", increased pre-load, and impaired heart function that eventually leads to more episodes of IDH, thus creating a vicious cycle.

To date, most studies have focused on alterations in pre-dialysis BP after PTX. Under the hypothesis that PTX may be associated with improved arterial stiffness and IDH that stabilize hemodynamic status and heart performance, this study aimed to analyze the IDH frequency and cardiovascular function before and after PTX in patients under maintenance hemodialysis.

\section{Materials and Methods}

\section{Study design and subjects}

Twenty-one hemodialysis patients who received total PTX with auto-transplantation of parathyroid tissue fragments at Taipei Veterans General Hospital between 2005 and 2011 were enrolled. All of them received long-term hemodialysis and were seen thrice weekly by their nephrologists for at least one year after PTX. Most had pre-operative PTH levels $>800 \mathrm{pg} / \mathrm{mL}$ associated with hypercalcemia and/or hyperphosphatemia that were refractory to medical therapy. Four patients had pre-operative PTH levels $>500 \mathrm{pg}$ / $\mathrm{mL}$ accompanied by mineral bone disorders. Patients who received previous renal transplant or PTX were excluded. The hospital's Institutional Review Board approved the study and the need for informed consent was waived because of the retrospective design.

The baseline characteristics of the study subjects, including age, sex, co-morbidities, causes of ESRD, and number of anti-hypertensive drugs (AHD), were obtained by review of medical records. Coronary heart disease was defined as the narrowing or blockage of coronary arteries in coronary angiography or ischemic changes in myocardial perfusion scans. Viral hepatitis carriers were defined as chronic HBV carriers or those with resolved HCV hepatitis status.

\section{Blood pressure measurement and biochemistry examination}

Hemodialysis was performed three times weekly (4 hours per session) using $1.8-\mathrm{m}^{2}$ surface area dialyzers with bicarbonate-based dialysates (sodium, $140 \mathrm{mEq} / \mathrm{L}$ [mmol/L]; bicarbonate, $39 \mathrm{mEq} / \mathrm{L}$ [mmol/L]; potassium, $2.0 \mathrm{mEq} / \mathrm{L}[\mathrm{mmol} / \mathrm{L}]$; calcium (serial changes shown in Table 2); and magnesium $1.0 \mathrm{mEq} / \mathrm{L}$ ) at $36^{\circ} \mathrm{C}$. The ultra-filtration strategy was linear to achieve dry weight. Measures undertaken to reduce IDH included a temporary reduction of the ultra-filtration and dialysate temperature, increasing the dialysate sodium level, or the use of midodrine or hyper-osmolar solution. The assessment of dry weight relied primarily on the clinical evaluation of the patient's hydration by experienced nephrologists. Brachial BP was measured with an oscillometric device. The hemodialysis data of each patient at time points of 1 month before, and 6 and 12 months post-PTX, including pre- and intra-dialysis BP, body weight, ultrafiltration volume, and dialysate composition at each dialysis session, were obtained.

The mean values from 13 dialysis sessions ( 1 month) at these three time points were calculated. Intradialysis BP was checked at least 4 times during each dialysis session, while IDH was defined as a decrease in $\mathrm{SBP} \geq 20 \mathrm{mmHg}$ or a decrease in MAP $\geq 10 \mathrm{mmHg}$ [9]. The Kt/V and the number of AHD prescribed were also recorded at each time point. The pre-dialysis laboratory tests before and after PTX included serum albumin, calcium (Ca), phosphate (P), alkaline phosphatase, hematocrit, and intact PTH levels. 


\section{Kidney Blood Pressure Research}

Kidney Blood Press Res 2013;37:323-331

\begin{tabular}{l|l}
\hline DOI: $10.1159 / 000350160$ & C 2013 S. Karger AG, Basel
\end{tabular}

Published online: September 22, 2013 www.karger.com/kbr

Shih/Tarng/Yang/Yang: Reduction of IDH after PTX
Evaluation of ventricular function and cardiothoracic ratio

All of the patients received annual routine assessment of ventricular function by first pass radionuclide ventriculography using technetium 99m pertechnetate and chest X-ray (CXR) 1 month before and 1 year after PTX to compare alterations in heart function. Cardiothoracic ratios (CTRs) were obtained from post-dialysis CXR in a standing position (posterior-anterior view) and calculated by dividing the maximal transverse diameter of the cardiac silhouette by the transverse inner diameter of the rib cage. Assessment of heart function was performed around the time of the blood tests.

\section{Statistical analysis}

Data were expressed as mean \pm standard deviation (SD) or inter-quartile range, where indicated. One-way repeated-measures analysis of variance (ANOVA) was used to detect significant differences between baseline and at 6 and 12 months. For heart function, only comparisons of baseline and 12 months were performed. Univariate simple regression analysis was used to assess the linear relationship between parameters. Statistical significance was set at $\mathrm{p}<0.05$. All of the statistical analyses were performed using SPSS version 19.0 (SPSS Inc., Chicago, IL, USA).

\section{Results}

\section{Patient characteristics}

The demographic data of the enrolled patients are shown in Table 1. The patients' mean age at the time of PTX was $57.4 \pm 12.0$ years. Of the 21 patients, seven were male $(33.3 \%)$ and 14 were female $(66.6 \%)$. The mean vintage of hemodialysis before PTX was $12.2 \pm 5.8$ years. The most prevalent co-morbidities were hypertension (76.2\%), diabetes mellitus (14.3\%), coronary artery disease (23.8\%), and chronic viral hepatitis $(23.8 \%)$. The etiologies of ESRD included hypertension in 2 (9.5\%) patients, diabetes mellitus in 3 (14.3\%), chronic glomerulonephritis in 3 (14.3\%), chronic interstitial nephritis in $3(14.3 \%)$, polycystic kidney disease in $3(14.3 \%)$, obstructive nephropathy in $2(9.5 \%)$, and unknown in $5(23.8 \%)$.

\section{Effects of PTX on pre- and intra-dialysis BP and IDH}

The serial changes in pre- and intra-dialysis BP are listed in Table 2. Compared to baseline (one month pre-PTX), pre-dialysis systolic BP (SBP), diastolic BP (DBP), mean arterial pressure (MAP), and PP were reduced significantly at 6 months post -PTX (M6). There were still significant reductions in DBP and MAP at 12 months post -PTX (M12). Reductions in SBP and PP tended to proceed until M12, but did not reach statistical significance ( $p=0.438$ for SBP; $p=0.085$ for PP).

At baseline and at 6- and 12-months post-PTX, the one-month dialysis sessions were interrupted by IDH $6.4 \pm 3.7$ times, $3.9 \pm 2.3$ times ( $p<0.016$ compared to baseline), and $4.0 \pm 3.1$ times ( $p<0.037$ compared to baseline, $p=0.801$ compared to 6 months post-PTX), respectively (Figure 1 ).
Table 1. Demographic data

Anti-hypertensive drugs, $n(\%)$

ACEI/ARB

$2.85 \pm 4.03$

Data are expressed as mean \pm SD or number (percentage) unless otherwise listed. Abbreviations: ACEI, angiotensin-converting- enblocker; AHD, anti-hypertensive drugs 


\section{Kidney \\ Blood Pressure Research}

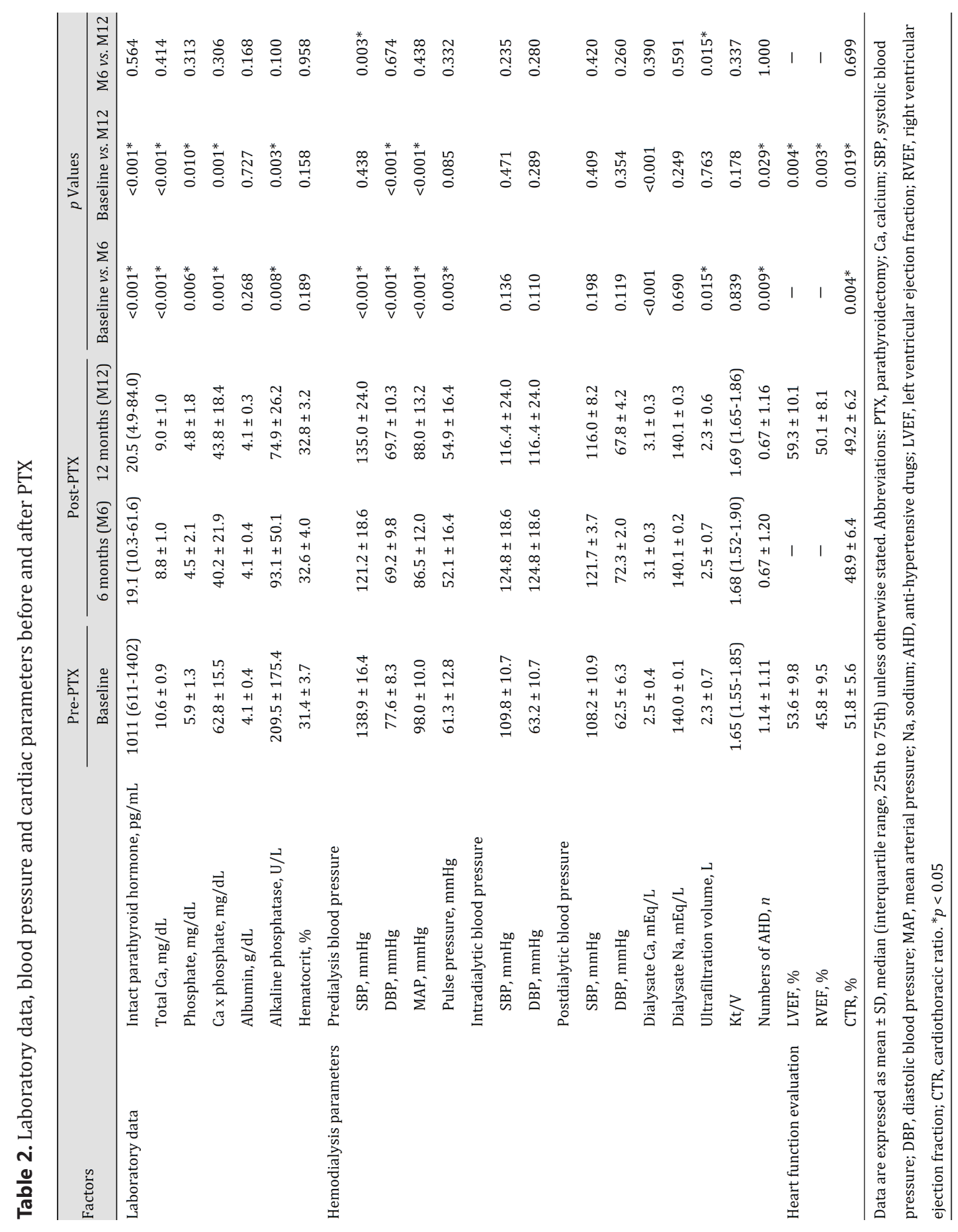

Pre- and post-dialysis body weight and prophylactic use of midodrine were not significantly different at the different time points. The mean ultra-filtration volume was significantly greater at 6 months post-PTX than at baseline, but was similar between baseline and 12 months post-PTX. The need of AHD was also reduced significantly for at least 1 year (Table 2). However, serial changes in midodrine dosage and number of AHD were not significantly correlated with changes in IDH. Thus, the effects of reduced IDH after PTX lasted for at least 12 months even though the ultra-filtration volume was greater. 


\section{Kidney Blood Pressure Research}

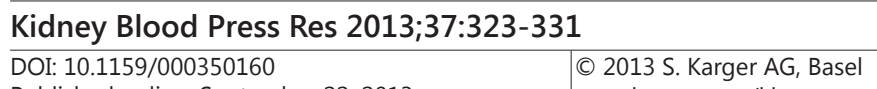

Published online: September 22, 2013 www.karger.com/kbr

Shih/Tarng/Yang/Yang: Reduction of IDH after PTX
Effects of PTX on laboratory values

The median PTH level declined significantly from $1011.0 \mathrm{pg} / \mathrm{mL}$ to 19.1 and to $20.5 \mathrm{pg} / \mathrm{mL}$ at 6 and 12 months post-PTX, respectively (Table 2). Levels of $\mathrm{Ca}, \mathrm{P}$, alkaline phosphatase, and Ca X $P$ products also decreased significantly. Although the significant increase in dialysate calcium level after PTX may have confounded the reduction in IDH episodes, there was no correlation with reduced IDH episodes (Figure 2). There were no differences in hematocrit and albumin levels before and after PTX.

\section{Effects of PTX on ventricular function} and volume status

Compared to baseline, values of left

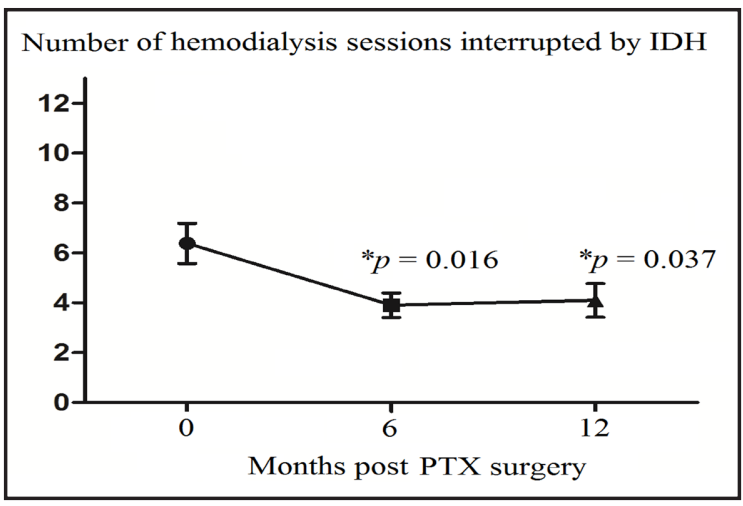

Fig. 1. Comparison of the number of hemodialysis sessions interrupted by intradialytic hypotension (IDH) in 13 consecutive sessions before and after parathyroidectomy (PTX).

and right ventricular ejection fraction (LVEF and RVEF) improved significantly at 12-months post-PTX (LVEF: $59.3 \pm 10.1 \%$ vs. $53.6 \pm 9.8 \%, p=0.004$; RVEF: $50.1 \pm 8.1 \%$ vs. $45.8 \pm 9.5 \%$, $p=0.003)$. The CTR also significantly decreased after PTX.

\section{Discussion}

The current study demonstrates that IDH is significantly reduced after PTX in maintenance hemodialysis patients with severe SHPT. Frequent IDH disrupts dialysis efficiency and efficacy, and is associated with higher morbidity and mortality [10-12]. The causes of IDH include cardiovascular and neuro-hormonal systems failure to compensate for the acute vascular volume depletion during ultra-filtration [7, 13-16]. However, the effect of PTH on the pathogenesis of IDH is unclear. The aim of the current study is to elucidate the association between SHPT and IDH.

In general, symptomatic hypotension occurs in $20-30 \%$ of dialysis sessions $[17,18]$. In this study, the incidence rates before PTX, and at 6 and 12 months after PTX are 49\%, $30 \%$, and $32 \%$, respectively. Hyper-parathyroidism may play a pivotal role in IDH as SHPT is associated with endothelial dysfunction and arterial stiffness in hemodialysis patients [15, 16]. Lowering PTH levels can ameliorate arterial calcification in uremic rats as well as in patients with primary or renal hyperparathyroidism [19-21].

Although pulse wave velocity was not measured in the current study, another arterial stiffness indicator, PP, was significantly decreased after PTX [22]. Impaired vascular elastic properties and reduced arterial compliance may cause hemodynamic instability and lead to an increased risk of IDH $[8,23]$. Previous studies have reported that ventricular stiffness at end-systole is also correlated with volume status in hemodialysis patients [6,24]. Therefore, as shown here, fewer IDH events may be associated with better volume status control, probably through improved arterial stiffness or cardiac status.

In the current study, pre-dialysis BP is reduced at 6 to 12 months after PTX. The BP-lowering effect of PTX has also been reported in patients with primary hyperparathyroidism, $[25,26]$, in hemodialysis patients with SHPT,[27-29], and in renal allograft recipients with SHPT $[30,31]$. Generally, vascular calcification and arterial stiffness may be major contributors to hypertension in hemodialysis patients with SHPT [2, 4]. However, the mechanisms of the BP-lowering effect after PTX remain unclear. In an animal study, PTX can reverse increased pulmonary calcification and reduce pulmonary hypertension [32]. In a small-scale human study, similar results of decreased arterial stiffness-have been noted after treatment with a calcimimetic agent $[3,20]$. 


\section{Kidney Blood Pressure Research}

In the present study, PTX is associated with subsequent reductions in IDH and PP, which may partly explain the improved BP control post-PTX. Thus, improved arterial stiffness may be responsible for the better pre-dialysis BP control after a drastic reduction in PTH level.

Previous experimental studies reveal that PTH is associated with myocardial hypertrophy, stunning, and fibrosis [33-35]. Moreover, PTX has been reported to improve long-term survival in dialysis patients with SHPT $[36,37]$. The current study shows the positive impact on systolic heart function of withdrawing PTH stimulation. Similarly, Drueke et al. [38] have disclosed that the LVEF of hemodialysis patients significantly improve oneto-two weeks after PTX. Moreover, Gafter et al. [39] demonstrated that PTX is beneficial for patients with cardiac dysfunction prior to PTX. Ohara et al. [40] have also shown that diastolic function improves after PTX in patients with primary hyper-parathyroidism.

Fig. 2. Relationships between $D$ the change in intradialytic hypotension (IDH) episodes and change in dialysate calcium level; (A) baseline vs. 6 months after parathyroidectomy (PTX) ( $\mathrm{r}=-0.440, \mathrm{p}$ $=0.851)$, $(\mathrm{B})$ baseline vs. 12 months after PTX ( $\mathrm{r}=0.140$, $\mathrm{p}=0.545)$, and (C) 6 months vs. 12 months after PTX ( $\mathrm{r}=$ 0.090, $\mathrm{p}=0.699$ ).
Kidney Blood Press Res 2013;37:323-331

\begin{tabular}{l|l}
\hline DOI: $10.1159 / 000350160$ & C 2013 S. Karger AG, Basel
\end{tabular}

Published onlIne: September 22, 2013 www.karger.com $/ \mathrm{kbr}$
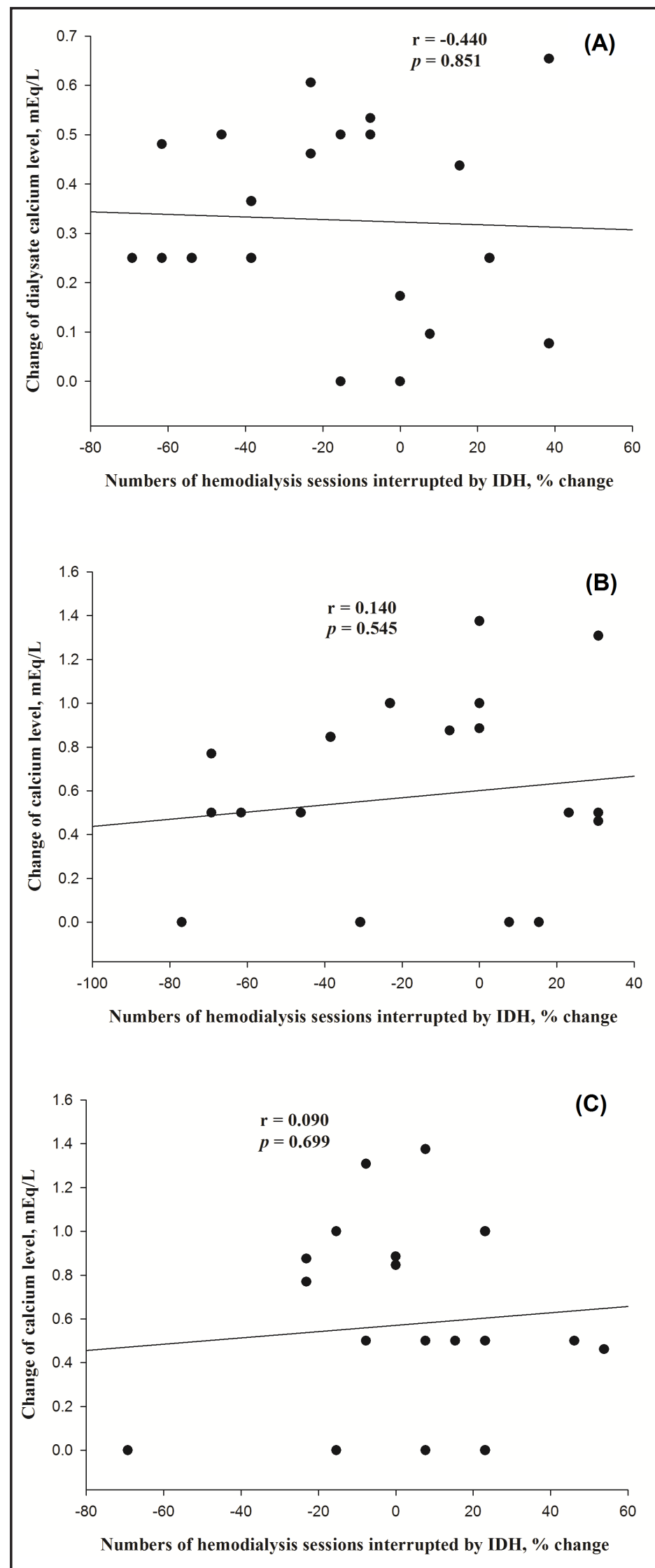


\section{Kidney \\ Blood Pressure Research}

Therefore, it can be posited that PTX provides an effective and promising strategy for dialysis patients with severe SPHT for improving heart function and volume control beyond targeting mineral bone disorders.

\section{Limitations}

First, this is a single-center study with an observational design and relatively small sample size. As such, it is not possible to examine a cause-effect relationship and only hypotheses may be proposed. Second, the widened PP is associated with pulse wave velocity and is regarded as an indirect indicator of increased arterial stiffness [41, 42]. Although PP does not directly indicate arterial stiffness, it is associated with strong end points like myocardial infarction, congestive heart failure, and even cardiovascular mortality [43-45]. Third, serial CTRs are only indirect markers of hydration. Nonetheless, the strength of this study is the inclusion of a detailed analysis of intra-dialysis BP, exact recordings of IDH, and heart function examinations by radionuclide ventriculography before and after PTX.

\section{Conclusions}

Parathyroidectomy reduces pre-dialysis BP and the number of IDH episodes, increases ultra-filtration volume, and improves the heart function of patients with severe SHPT. These novel findings suggest that the reduced IDH after PTX may act as a braking system that prevents the vicious cycle of inadequate dialysis, fluid overload, and heart failure. Moreover, PTX seems to reverse such adverse effects to achieve normotension and euvolemia, probably through improved heart function and reduced episodes of IDH. Further prospective trials are warranted.

\section{Conflicts of Interest}

None.

\section{References}

1 Ganesh SK, Stack AG, Levin NW, Hulbert-Shearon T, Port FK: Association of elevated serum po(4), ca x po(4) product, and parathyroid hormone with cardiac mortality risk in chronic hemodialysis patients. J Am Soc Nephrol 2001;12:2131-2138.

2 Covic A, Gusbeth-Tatomir P, Goldsmith DJA: Arterial stiffness in renal patients: An update. Am J Kidney Dis 2005;45:965-977.

-3 de Francisco AL, Pinera C, Palomar R, Arias M: Impact of treatment with calcimimetics on hyperparathyroidism and vascular mineralization. J Am Soc Nephrol 2006;17:S281-285.

- 4 Nitta K, Akiba T, Uchida K, Otsubo S, Otsubo Y, Takei T, Ogawa T, Yumura W, Kabaya T, Nihei H: Left ventricular hypertrophy is associated with arterial stiffness and vascular calcification in hemodialysis patients. Hypertens Res (Japan) 2004;27:47-52.

5 Laurent S, Boutouyrie P, Asmar R, Gautier I, Laloux B, Guize L, Ducimetiere P, Benetos A: Aortic stiffness is an independent predictor of all-cause and cardiovascular mortality in hypertensive patients. Hypertension 2001;37:1236-1241.

6 Chen CH, Lin YP, Yu WC, Yang WC, Ding YA: Volume status and blood pressure during long-term hemodialysis: Role of ventricular stiffness. Hypertension 2003;42:257-262.

-7 Yamamoto K, Kobayashi N, Kutsuna T, Ishii A, Matsumoto T, Hara M, Aiba N, Tabata M, Takahira N, Masuda T: Excessive fall of blood pressure during maintenance hemodialysis in patients with chronic renal failure is induced by vascular malfunction and imbalance of autonomic nervous activity. Ther Apher Dial 2012;16:219-225. 


\section{Kidney \\ Blood Pressure Research}

8 Duman D, Demirtunc R, Erdogan B, Sahin GM, Karadag B: Dialysis-induced hypotension is associated with impaired aortic elasticity in patients undergoing chronic hemodialysis. Blood Press Monit 2008;13:73-78.

-9 K/DOQI clinical practice guidelines for cardiovascular disease in dialysis patients. Am J Kidney Dis 2005;45:S1-153.

10 Tisler A, Akocsi K, Borbas B, Fazakas L, Ferenczi S, Gorogh S, Kulcsar I, Nagy L, Samik J, Szegedi J, Toth E, Wagner G, Kiss I: The effect of frequent or occasional dialysis-associated hypotension on survival of patients on maintenance haemodialysis. Nephrol Dial Transplant 2003;18:2601-2605.

11 Henderson LW: Symptomatic intradialytic hypotension and mortality: An opinionated review. Semin Dialysis 2012;25:320-325.

-12 Inrig JK, Oddone EZ, Hasselblad V, Gillespie B, Patel UD, Reddan D, Toto R, Himmelfarb J, Winchester JF, Stivelman J, Lindsay RM, Szczech LA: Association of intradialytic blood pressure changes with hospitalization and mortality rates in prevalent esrd patients. Kidney Int 2007;71:454-461.

13 Daugirdas JT: Pathophysiology of dialysis hypotension: An update. Am J Kidney Dis 2001;38:S11-S17.

14 Perazella MA, Rho M, Brewster UC: Vasopressin insufficiency and intradialytic hypotension. Am J Kidney Dis 2008;52:1197.

15 Rashid G, Bernheim J, Green J, Benchetrit S: Parathyroid hormone stimulates endothelial expression of atherosclerotic parameters through protein kinase pathways. Am J Physiol Renal Physiol 2007;292:F1215-F1218.

16 Coen G, Mantella D, Sardella D, Beraldi MP, Ferrari I, Pierantozzi A, Lippi B, Di Giulio S: Asymmetric dimethylarginine, vascular calcifications and parathyroid hormone serum levels in hemodialysis patients. J Nephrol 2009;22:616-622.

17 Palmer BF, Henrich WL: Recent advances in the prevention and management of intradialytic hypotension. J Am Soc Nephrol 2008;19:8-11.

18 Chen IJ, Chang MY, Chiao SL, Chen JL, Yu CC, Yang SH, Liu JM, Hung CC, Yang RC, Chang HC, Hsu CH, Fang JT: Korean red ginseng improves blood pressure stability in patients with intradialytic hypotension. Evid Based Complement Alternat Med 2012;2012:595271.

19 Kawata T, Nagano N, Obi M, Miyata S, Koyama C, Kobayashi N, Wakita S, Wada M: Cinacalcet suppresses calcification of the aorta and heart in uremic rats. Kidney Int 2008;74:1270-1277.

20 Bonet J, Bayes B, Fernandez-Crespo P, Casals M, Lopez-Ayerbe J, Romero R: Cinacalcet may reduce arterial stiffness in patients with chronic renal disease and secondary hyperparathyroidism - results of a smallscale, prospective, observational study. Clin Nephrol 2011;75:181-187.

21 Schillaci G, Pucci G, Pirro M, Monacelli M, Scarponi AM, Manfredelli MR, Rondelli F, Avenia N, Mannarino E: Large-artery stiffness: A reversible marker of cardiovascular risk in primary hyperparathyroidism. Atherosclerosis 2011;218:96-101.

22 Briet M, Pierre B, Laurent S, London GM: Arterial stiffness and pulse pressure in ckd and esrd. Kidney Int 2012;82:388-400.

23 Dubin R, Owens C, Gasper W, Ganz P, Johansen K: Associations of endothelial dysfunction and arterial stiffness with intradialytic hypotension and hypertension. Hemodial Int 2011;15:350-358.

24 de Simone G: Left ventricular geometry and hypotension in end-stage renal disease: A mechanical perspective. J Am Soc Nephrol 2003;14:2421-2427.

25 Rydberg E, Birgander M, Bondeson AG, Bondeson L, Willenheimer R: Effect of successful parathyroidectomy on 24-hour ambulatory blood pressure in patients with primary hyperparathyroidism. Int J Cardiol 2010;142:15-21.

26 Heyliger A, Tangpricha V, Weber C, Sharma J: Parathyroidectomy decreases systolic and diastolic blood pressure in hypertensive patients with primary hyperparathyroidism. Surgery 2009;146:1042-1047.

-27 Pizzarelli F, Fabrizi F, Postorino M, Curatola G, Zoccali C, Maggiore Q: Parathyroidectomy and blood pressure in hemodialysis patients. Nephron 1993;63:384-389.

-28 Goldsmith DJ, Covic AA, Venning MC, Ackrill P: Blood pressure reduction after parathyroidectomy for secondary hyperparathyroidism: Further evidence implicating calcium homeostasis in blood pressure regulation. Am J Kidney Dis 1996;27:819-825.

-29 Almirall J, Lopez T, Comerma I, Garcia E, Marques G: Effect of parathyroidectomy on blood pressure in dialysis patients. Nephron 2002;92:495-496. 


\section{Kidney \\ Blood Pressure Research}

Shih/Tarng/Yang/Yang: Reduction of IDH after PTX

-30 Evenepoel P, Claes K, Kuypers D, Maes B, Vanrenterghem Y: Impact of parathyroidectomy on renal graft function, blood pressure and serum lipids in kidney transplant recipients: A single centre study. Nephrol Dial Transplant 2005;20:1714-1720.

-31 Pajda M, Matug A, Widlak M, Antoniak K, Ficek R, Chudek J, Wiecek A: Influence of parathyroidectomy on blood pressure and function of the transplanted kidney in patients with tertiary hyperparathyroidism. Ann Transplant 2006;11:11-15.

-32 Akmal M, Barndt RR, Ansari AN, Mohler JG, Massry SG: Excess pth in crf induces pulmonary calcification, pulmonary hypertension and right ventricular hypertrophy. Kidney Int 1995;47:158-163.

-33 Rodriguez-Ayala E, Avila-Diaz M, Foyo-Niembro E, Amato D, Ramirez-San-Juan E, Paniagua R: Effect of parathyroidectomy on cardiac fibrosis and apoptosis: Possible role of aldosterone. Nephron Physiol 2006;103:112-118.

34 Smogorzewski M, Perna AF, Borum PR, Massry SG: Fatty acid oxidation in the myocardium: Effects of parathyroid hormone and crf. Kidney Int 1988;34:797-803.

-35 Bogin E, Massry SG, Harary I: Effect of parathyroid hormone on rat heart cells. J Clin Inv 1981;67:12151227.

36 Iwamoto N, Sato N, Nishida M, Hashimoto T, Kobayashi H, Yamasaki S, Ono T, Nishimura M, Tokoro T, Sakoda C, Murakawa M, Okino K, Okamoto Y, Imai R, Adachi N, Ninomiya K, Mabuchi H, Koyama M, Nakanouchi T, Iseki K: Total parathyroidectomy improves survival of hemodialysis patients with secondary hyperparathyroidism. J Nephrol 2012;25:755-763.

37 Sharma J, Raggi P, Kutner N, Bailey J, Zhang R, Huang Y, Herzog CA, Weber C: Improved long-term survival of dialysis patients after near-total parathyroidectomy. J Am Coll Surg 2012;214:400-407; discussion 407 408.

-38 Drueke T, Fauchet M, Fleury J, Lesourd P, Toure Y, Le Pailleur C, de Vernejoul P, Crosnier J: Effect of parathyroidectomy on left-ventricular function in haemodialysis patients. Lancet 1980;1:112-114.

-39 Gafter U, Battler A, Eldar M, Zevin D, Neufeld HN, Levi J: Effect of hyperparathyroidism on cardiac function in patients with end-stage renal disease. Nephron 1985;41:30-33.

40 Ohara N, Hiramatsu K, Shigematsu S, Hayashi Y, Ishihara F, Aizawa T, Niwa A, Yamada T, Hashizume $\mathrm{K}$ : Effect of parathyroid hormone on left ventricular diastolic function in patients with primary hyperparathyroidism. Miner Electrolyte Metab 1995;21:63-66.

41 Ni Y, Wang H, Hu D, Zhang W: The relationship between pulse wave velocity and pulse pressure in chinese patients with essential hypertension. Hypertension Res (Japan) 2003;26:871-874.

42 Abhayaratna WP, Srikusalanukul W, Budge MM: Aortic stiffness for the detection of preclinical left ventricular diastolic dysfunction: Pulse wave velocity versus pulse pressure. J Hypertension 2008;26:758764.

43 Benetos A, Safar M, Rudnichi A, Smulyan H, Richard JL, Ducimetieere P, Guize L: Pulse pressure: A predictor of long-term cardiovascular mortality in a french male population. Hypertension 1997;30:1410-1415.

-44 Franklin SS, Khan SA, Wong ND, Larson MG, Levy D: Is pulse pressure useful in predicting risk for coronary heart disease? The framingham heart study. Circulation 1999;100:354-360.

45 Chae CU, Pfeffer MA, Glynn RJ, Mitchell GF, Taylor JO, Hennekens CH: Increased pulse pressure and risk of heart failure in the elderly. J Am Med Assoc 1999;281:634-639. 